\section{Peptic ulcer disease precipitating duodenal intussusception}

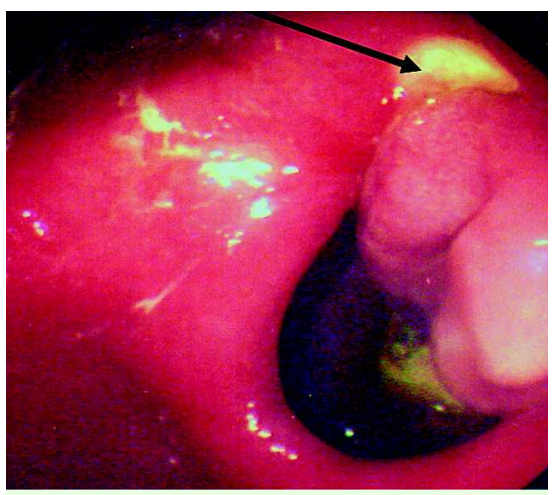

Fig. 1 Endoscopic image showing a pyloric channel ulcer (arrow) and prolapse of a sleeve of the proximal duodenum into the gastric antrum through the pylorus.

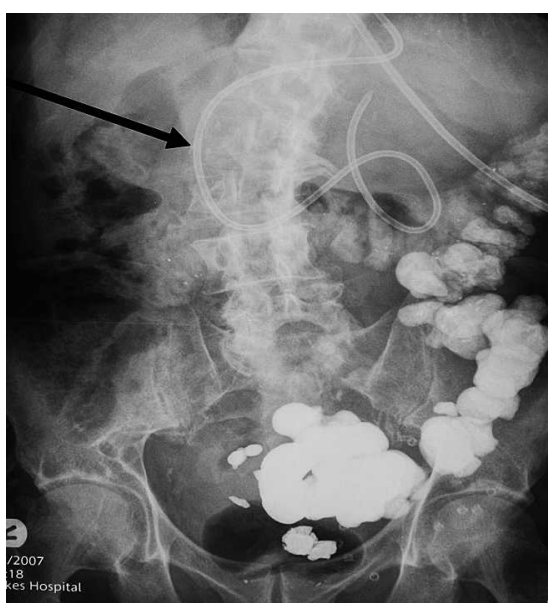

Fig. 2 Abdominal radiograph showing satisfactory placement of nasobiliary tube (arrow) in the proximal small bowel.

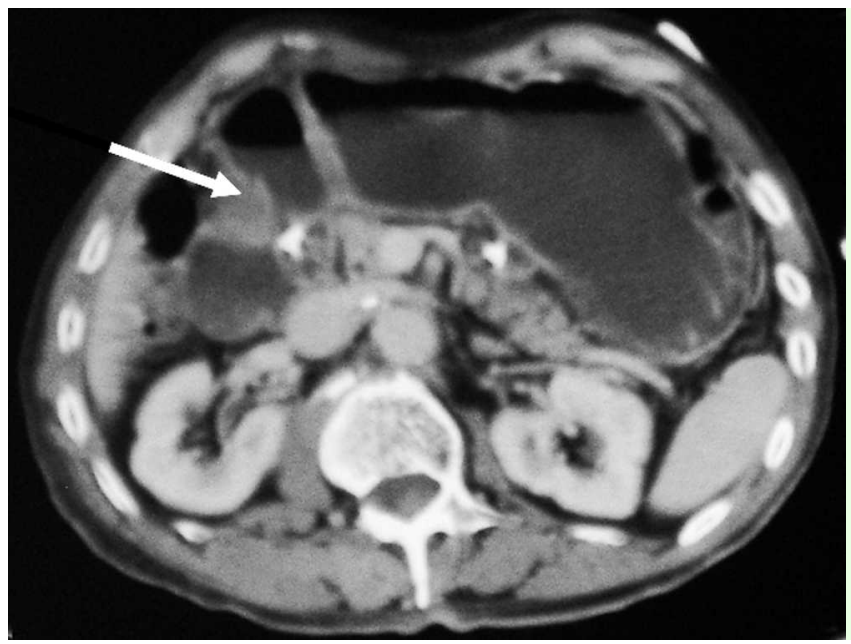

A 71-year-old male presented with a 6 week history of vomiting and a $10 \mathrm{~kg}$ weight loss. He was taking aspirin. Gastroscopy demonstrated a small pyloric channel Helicobacter pylori-negative ulcer. Duodenal intubation was obstructed by prolapse of the proximal duodenum into the gastric antrum ( $\bullet$ Fig. 1). The gastroscope was maneuvered beyond the prolapse over an endoscopic retrograde cholangiopancreatography catheter (Tandem XL; Boston Scientific, Natick, Massachusetts, USA) preloaded with a 0.035 inch guide wire (Jagwire; Boston Scientific) reducing the intussusception. A $10 \mathrm{Fr}$ nasobiliary tube (ENBD; Cook Medical Inc., Bloomington, Indiana, USA) was placed into the jejunum to facilitate nutrition and maintain the reduced intussusception ( $\bullet$ Fig. 2).

Computed tomography imaging excluded extrinsic compression ( $\bullet$ Fig. 3 ). The patient commenced proton pump inhibitor therapy. The feeding tube was removed after 4 weeks, and the patient's weight had increased by $8 \mathrm{~kg}$. Two months following the tube removal, the patient was asymptomatic with further weight gain of $12 \%$.

Intussusception typically involves distal prolapse of the full thickness of the bowel wall [1]. Duodenal intussusception is rare because the duodenum is predominantly retroperitoneal and fixed in position. It has been associated with ampullary tumors as the provoking point [2]. The first part of the duodenum is intraperitoneal suspended from the posterior wall of the abdomen by visceral adipose tissue. Doucet et al. demonstrated that a reduction in weight results in loss of visceral adipose tissue [3]. The vomiting precipitated by the pyloric channel ulcer probably initiated the prolapse by sustained reversed peristalsis. The ensuing weight loss resulted in visceral fat loss further facilitating the intussusception. Reduction and stabilization of the intussusception allowed the patient to regain lost weight, thus restrengthening the intraperitoneal support and preventing the intussusception from recurring. This plus the proton pump inhibitor therapy allowed the ulcer to heal prior to the tube removal. Peptic ulcer disease as the provoking point for duodenal intussusception has not been previously reported.

Endoscopy_UCTN_Code_CCL_1AB_2AZ_3AC

\section{F. Donnellan, F. Zeb, G. Courtney, \\ A. R. Aftab}

Department of Gastroenterology, St. Luke's Hospital, Kilkenny, Ireland

\section{References}

1 Vinces FY, Ciacci J, Sperling DC, Epstein S. Gastroduodenal intussusception secondary to a gastric lipoma. Can J Gastroenterol 2005; 19: $107-108$

2 Chalmers N, De Beaux AC, Garden OJ. Case report: prolapse of an ampullary tumour beyond the duodeno-jejunal flexure. Clin Radiol 1993; 47: 141 - 142

3 Doucet E, St-Pierre S, Alméras N et al. Reduction of visceral adipose tissue during weight loss. Eur J Clin Nutr 2002; 56: 297 304

\section{Bibliography}

DOI $10.1055 / \mathrm{s}-2007-995806$

Endoscopy 2008; 40: E176

(c) Georg Thieme Verlag KG Stuttgart · New York . ISSN 0013-726X

Corresponding author

\section{A. R. Aftab, MD}

Consultant Gastroenterologist

St. Luke's Hospital

Kilkenny

Ireland

Fax: +353-56-7785172

aftabar@hotmail.com 